\title{
O QUE É SER UM INTELECTUAL PÓS-MODERNO? \\ UMA ESTRATÉGIA DO PÓS-MODERNO DIANTE DO \\ PROJETO EMANCIPATÓRIO MARXIANO DOHOMEM
}

\section{WHAT IS TO BE A POST-MODERN INTELLECTUAL? \\ A STRATEGY FOR THE POST-MODERN FACE OF \\ MARXIAN EMANCIPATORY PROJECT MAN}

\author{
Jean Paulo Pereira de MENEZES \\ Mestre em História pela FCH/UFGD-MS, \\ Docente do curso de Serviço Social e Pedagogia da Unilago-SP.
}

RESUMO: Este artigo pretende apresentar algumas contribuições ao debate teórico acerca da modernidade e a invenção da pós-modernidade, apenas no sentido de apontamentos críticos para uma concepção de história e tempo presente imediato na sociedade de classes antagônicas. Metodologicamente, o artigo faz parte da construção metodológica do trabalho de pesquisa para doutoramento em História em andamento.

Palavras-chave: Modernidade - lluminismo - marxismo e pósmodernidade.

ABSTRACT: This article presents some contributions to the theoretical debate about the invention of modernity and postmodernity, only in the sense of critical points to a conception of history and present time in the immediate society of antagonistic classes. Methodologically, the article is part of the construction methodology of the research work for Ph.D. in History in progress.

Key-words: modernity - Enlightenment - Marxism and postmodernism.

\section{Introdução}

Antes de mais nada, iniciemos apresentando o que é ser um intelectual, para podermos melhor entender o termo substantivado (intelectual pósmoderno).

A palavra intelectual passou a ser empregada a partir de 1898 em Paris para se referir a Emille Zola e seus correligionários que buscavam inferirem através da crítica no espaço público da política francesa. De início a palavra intelectual foi carregada de uma depreciação, pois os intelectuais de Zola eram entendidos pelo governo francês como alguma espécie de bisbilhoteiros da 
política do tempo presente ${ }^{1}$. Assim mesmo, o termo intelectual pegou e passou a ser um designativo nada pejorativo, uma vez que o intelectual buscava a preservação dos valores burgueses universais como liberdade, justiça etc.

Certamente, dos tempos de Zola até nossos dias, diversos tipos de intelectuais existiram e o conceito também se transformou, principalmente após Marx. E, entre as novas ${ }^{2}$ configurações intelectuais podemos observar: o intelectual pós-moderno.

Se inicialmente, ser um intelectual era a emblematização de posicionar-se publicamente, valendo-se da isonomia e da isegoria, com o desenvolver da tradição marxista, o posicionamento do intelectual vai alçar vôos mais longos, principalmente após Antonio Gramsci.

O conceito de intelectual em Gramsci é muito mais amplo. O intelectual no sentido gamsciano não é necessariamente apenas o palestrante, o literato, os homens das letras diante de seus posicionamentos. Para Gramsci, intelectual é todo sujeito que exerce uma intelecção. Assim, todos os sujeitos são intelectuais. Certamente nem todo sujeito histórico exerce uma função de intelectual na sociedade do trabalho, da mesma forma que nem todo mundo exerce a função de alfaiate ou pedreiro na mesma sociedade do trabalho, porém, nem por isso deixam de saberem costurar ou assentarem tijolos eventualmente. Todavia:

Quando se distingue entre intelectuais e não-intelectuais, fazse referência, na realidade, tão-somente á imediata função social da categoria profissional dos intelectuais, isto é, leva-se em conta a direção sobre a qual incide o peso maior da atividade profissional específica, se na elaboração intelectual ou se no esforço muscular-nervoso. Isto significa que, se se pode falar de intelectuais, é impossível falar de nãointelectuais, porque não existem não-intelectuais.Mas a própria relação entre o esforço de elaboração intelectual-cerebral e o esforço' muscular-nervoso não é sempre igual; por isso, existem graus diversos de atividade específica intelectual. Não existe atividade humana da qual se possa excluir toda

\footnotetext{
1 A história do tempo presente que postulamos é fundada na dialética marxiana como método de entendimento da História. Um instrumento teórico-metodológico que nos possibilitou entender o objeto em uma chave ontológica e não apenas como um objeto empiricamente ao léu do processo histórico das aparências sensíveis.

${ }^{2}$ Se pensarmos que muitos dos elementos presentes nos intelectuais pós-modernos já remontam à Kant, seria prudente considerarmos que esse novo não é tão novo como sugere o termo. Muito do que se defende hoje, os pós-modernos, já é velho conhecido da História.
} 
intervenção intelectual, não se pode se parar o homo faber do homo sapiens (GRAMSCI, 1982:07).

Essas considerações se fazem necessárias diante da existência da considerável literatura na historiografia brasileira que se assenta no conceito tradicional de intelectual. Não identificamos uma tradição historiográfica que se baseie em uma produção a partir do conceito proposto por Gramsci sobre os intelectuais. Pelo avesso, localizamos, salvo as poucas exceções (KONDER, 1991) uma tradição calcada no conceito de intelectuais que Gramsci entende como tradicionais. Isso se verifica nos trabalhos de Heloisa Pontes (PONTES, 1997 e 1998), Sérgio Miceli (MICELI, 2001), José Geraldo Vinci de Moraes (MORAES, 2001), isso só para ficarmos entre alguns dos emblemáticos com alto transito entre os historiadores brasileiros. Entendemos que ao trabalharem nesta chave do conceito de intelectuais, esses autores também estabelecem limites no que tange ao entendimento de uma categoria tão complexa como essa na sociedade de classes, contribuindo para o apartamento da classe de trabalhadores daquilo que é construído e acumulado historicamente pelo ser, numa palavra, sua capacidade intelectual.

A posição epistêmica ${ }^{3}$ do intelectual segue por variados referenciais, do positivismo ao pós-modernismo contemporâneo, passando também pelo estereótipo materialista dialético humanista. Assim, os intelectuais devem ser entendidos como uma massa cinzenta heterogênea catalisada pelas universidades e outras instituições ${ }^{4}$, onde representaram a sua vontade de poder individual/grupal ao qual pertence, e mesmo a vontade de poder individual/coletiva. Ambas representantes de uma sociologia da ciência já que não se limitam à produção epistemológica apenas para o bel prazer, pois a fazem conscientes ou parcialmente conscientes de que representam um recorte social.

\footnotetext{
${ }^{3} \mathrm{O}$ sentido epistêmico empregado aqui neste nosso trabalho se refere à organização do conhecimento de forma sistemática. Ao nos referirmos ao campo epistemológico não o fazemos com pretensões enciclopédicas, limitando-se assim ao referencial da produção e organização do conhecimento produzido.

${ }^{4}$ Partidos políticos, associações, sindicatos, etc.
} 
Evidentemente encontraremos na universidade e demais instituições, uma vasta rede de arquétipos de intelectuais. Alguns, despreocupados com a organização social, seja por representarem o recorte que se faz hegemônico da organização político-administrativa do Estado, ou, mesmo por estarem confortáveis diante de seu niilismo acerca da política que Ihes parece desinteressante sobre o interessante mundo das representações intelectuais as quais Ihes garantem títulos e honrarias, além de um salário estatal para reproduzirem de forma técnica os elementos favoráveis à manutenção do grupo político que administra a coisa pública. Outros, preocupados com a organização social e a instrumentalização de um novo grupo hegemônico que venha a substituir a hegemonia vigente do Estado. Referimo-nos ao intelectual orgânico de Antonio Gramsci, dotado de um engajamento diferente do primeiro e que se pretende capaz de representar o recorte social que não se efetiva no poder por não possuir suas ideologias consolidadas na sociedade marginal como umtodo.

Como podemos, a priori, apresentar, a Universidade acaba por se enquadrar ou ser enquadrada como uma paisagem de defesa do intelectual orgânico seja ele o da ideologia do estado vigente ou daquela que visa à busca da hegemonia no atual Estado. Em ambos os casos, os intelectuais postulam a representação das massas/classes populares, colocando-se em função de estudá-las e apresentá-las e mesmo de apresentar a elas o estudo que as representa na busca, seja pela manutenção da ordem vigente (que é a síntese geral dos intelectuais pós-modernos) ou pela luta consciente de classes marginais rumo à hegemonia de um novo estado de coisas.

\section{OIntelectual substantivado}

Diuturnamente, é muito provável que nos deparemos com os agentes da pós-modernidade. Seja através da literatura, filmes, peças teatrais, jornais, revistas, internet, universidades e os relacionamentos sociais do cotidiano.

O que chamamos de pós-modernidade, mais poderia ser chamado de uma grande nuvem cinzenta, com variados tons de cinza. Seria muito difícil e mesmo infantil, compreendermos a pós-modernidade como algo homogêneo e 
de fácil identificação coletiva. Trata-se de um conjunto de postulações, nem sempre presente em sua totalidade no discurso de todos os intelectuais pósmodernos. O que não inviabiliza a identificação de elementos centrais que constituem o paradigma pós-moderno.

Diante desta inicial problemática, vejamos mais proximamente alguns desses elementos constitutivos do que chamamos aqui de o paradigma pósmoderno: a)- a negação da totalidade; b)- a negação das grandes narrativas; c)- a centralidade do objeto; d)- o pluralismo metodológico, e; e)- a defesa da alteridade. Isso só para ficarmos com os mais emblemáticos elementos constitutivos do pensamento dito pós-moderno.

\section{a)- $A$ negação da totalidade}

O entendimento de que determinados eventos devem ser entendidos diante de uma totalidade complexa é abandonado pelo intelectual pós-moderno a favor da micro história, a preocupação com o fenômeno em si. Um texto, por exemplo, deveria ser analisado a partir dele mesmo, por si só, uma vez que as conexões de todo o seu processo produtivo lhe é inacessível pelo sujeito que empreende tal tipo de trabalho. A essência do fenômeno livro não é alçada como objeto de investigação por tratar-se de algo que foge as capacidades do sujeito, cabendo ao objeto a centralidade da questão.

A negação da totalidade implica na produção de um tipo de conhecimento encerrado no objeto, sensivelmente captado no cotidiano, detendo-se ao evento e não se preocupando com o processo, a totalidade que origina determinados fenômenos. Estuda-se a festa da Revolução Francesa e não o processo revolucionário. Estuda-se as manifestações da fome, mas não os elementos constitutivos da fomes nos corpos humanos. Estuda-se as representações imediatas e não os conceitos fundamentais das coisas.

\section{b)- $A$ negação das grandes narrativas}

Entendemos as grandes narrativas como propostas de entendimento de determinados fenômenos que levam em consideração a longa duração, os 
fundamentos ontológicos de constituição dos seres e suas relações diversas. $\mathrm{O}$ Intelectual pós-moderno entende que grandes narrativas são donas de pretenciosidade e que são incapazes de apreenderem todo o processo de longa duração do fenômeno. As grandes narrativas se enquadrariam em filosofias da história, pouco verificáveis diante da imprecisão de acesso ao fatos pretéritos e a impossibilidade de objetar o futuro. Certamente, a maioria dos pós-modernos se referem aqui, principalmente, aos intelectuais da tradição marxista. A negação das grandes narrativas se faz a favor da pequena narrativa, ou seja, da história micro, da história do cotidiano, do presentismo, do imediato, do relativamente palpável e do efêmero.

\section{c)- $A$ centralidade do objeto}

Para o intelectual pós-moderno o objeto é que detêm a centralidade interpretativa, pois o sujeito se encontra fragmentado diante da totalidade social, cabendo assim a compreensão de que a centralidade está no objeto, de que ele não é centralizador, pois ele é a centralidade, ou ainda, de que a centralidade está nele (objeto).

A relação entre sujeito e objeto não é compreendida como uma relação centrada no sujeito histórico. Não cabe mais ao sujeito a interpretação da realidade social, pois a concepção de realidade está centrada no objeto, sendo inacessível ao sujeito que não mais é o portador da centralidade das relações sociais, perdendo significância assim para o objeto: o novo centro dos significados.

O objeto fala por si próprio, não sendo possível ao sujeito a pré-ideação, menos ainda a objetivação da coisa em si. Desta maneira, ao identificar a centralidade das relações no objeto, o intelectual pós-moderno tributa ao sujeito um papel, na melhor das hipóteses, dependente deste na construção da história. Não nos enganemos com essa tal centralidade, pois uma mesa não determina as relações entre os homens, nem mesmo uma goiabeira cheia de goiabas produzidas na Argentina. O que determina as relações sociais, fenomênicas ou não, são os próprios indivíduos socialmente entendidos, ou seja, é no sujeito que se encontra a centralidade das relações sociais. São os 
sujeitos que realizam o trabalho sociamente necessário para o produto cadeira existir. São os sujeitos que dão vida ao setor da agricultura que se ocupa da plantação de pés - de- goiabas como produtos que irão para o mercado, portanto mercadorias existentes como produto da ação interventiva do sujeito diante da natureza.

O intelectual pós-moderno reduz a complexidade das relações sociais de produção em nome de uma simplificação do papel do indivíduo social na história quando reconhece no objeto a centralidade de todo o processo histórico das relações sociais. O paradigma pós-moderno, aqui, faz mais um grande serviço às relações sociais mistificadas na sociedade capitalista. Tira arbitrariamente o papel interventivo do sujeito histórico e a sua capacidade compressão da realidade concreta da qual é o personagem fundante. Presta também o (de)serviço ao tirar do sujeito a capacidade de transformação da realidade social plantada na exploração de classes economicamente distintas, contribuindo sobremaneira para a manutenção do estado de coisas vigente, tais como exploração do trabalho em todo o planeta, pois, entender as relações entre capital e trabalho seria, para o pós-moderno algo extremamente pretensioso e fora das possibilidades do sujeito, exceto através de uma filosofia da história que associam a uma espécie de religião da modernidade, prometedora do paraíso terrestre entre os homens (falaremos mais desta questão adiante).

\section{d)- O pluralismo metodológico}

Acredita-se que o pluralismo metodológico é a expressão das diversas visões de mundo, deixando assim os seus diversos olhares sobre os fenômenos sociais. A pluralidade aqui faz coro com o ideal de diversidade que defende a máxima: "de que quanto mais, melhor," para entender os fenômenos, ou seja, mais rico será o olhar daquele que observa. Uma forma bastante democrática de se fazer o celebrar das diferenças teóricometodológicas que constituem a história da humanidade. Não se preocupam em identificar a totalidades das realmente múltiplas perspectivas teóricas e metodológicas produzidas pelo ser social, esquecendo-se aqui, o intelectual 
pós-moderno, que todo o riquíssimo campo das teorias e métodos são as expressões dos momentos históricos vivido pelos sujeitos. Mais uma vez, aqui, a postura do paradigma em questão ignora a totalidade e os conflitos dessa totalidade socialmente construída. Tal postura contempla a harmonia onde impera o conflito, a idéia plural diante do concreto tangido pelo poder das relações sociais.

Entendemos que o pluralismo, ao se direcionar às perspectivas teóricas e metodológicas, podem gerar um campo complexo e perigoso, onde as perspectivas em jogo nem sempre são plausíveis de compressão daquilo que se estuda, analisa e edifica cognitivamente. Situações emblemáticas como àquelas em que se constrói em ciências históricas, propondo diálogos teóricos metodológicos pouco, ou nada, exeqüíveis, por exemplo: Pierre Clastres e Meillassoux; Michael Foucault e Henri Lefebvre, ou ainda, Karl Marx e Leopold Von Ranke. Salvo as singularidades de cada momento da trajetória intelectual desses autores, colocá-los ou mesmo elencá-los como sinonimais teoricamente e metodologicamente, seria um absurdo. Só para ficarmos com o primeiro caso, vejamos uma análise de Pierre Clastres sobre Meillassoux e Godelier em 1978, pouco antes do falecimento do primeiro autor:

Tome-se, por exemplo, Meillassoux. Ele seria, dizem, uma das cabeças pensantes (pensantes!) da antropologia marxista. Nesse caso preciso, esforços penosos me são poupados graças à análise detalhada que A. Adler dedicou a uma obra recente desse autor. [...] há algo de Monsenhor Lefebvre nesse homem: o mesmo fanatismo estreito, a mesma alergia incurável à duvida. [...] Mas Meillassoux não é o único, e seria injusto para os outros fazer pensar que ele detém o monopólio do marxismo antropológico. Por um cuidado de eqüidade, convém dar a seus colegas o lugar que merecem. Tome-se, por exemplo, Godelier. [...] Seu marxismo chama a atenção, pois parece menos áspero, mais ecumênico que o de Meillasoux. [...] Seria então um oportunista? Nada disso. É um atleta do pensamento, que empreendeu fazer a síntese entre estruturalismo e marxismo. É preciso vê-lo saltitar de Marx a Lévi-Strauss. (Saltitar? Como se fosse um passarinho? São guinadas de elefante!) (CLASTRES, 1978).

O caso citado aqui é emblemático das polêmicas acadêmicas engajadas e ilustra bem nossa preocupação como pluralismo metodológico 
como um dos elementos da pós-modernidade e a maior parte de seus intelectuais.

Com efeito, nada impossibilitaria o desenvolvimento de um estudo entre "deus" e o "diabo" e todos os seus seguidores, entretanto, não levar em consideração as múltiplas possíveis das perspectivas teórico-metodológicas que se postula, poderia, na melhor das hipóteses, promover uma construção sobre determinados problemas altamente fragilizada. Reafirmamos, não se trata de elencarmos perspectivas "amigas", mas da necessidade de clareza sobre essa questão para que não se redunde na vulgarização e na teoria do relativismo cognitivo presente no paradigma pós-moderno ${ }^{5}$.

\section{e)- $A$ defesa da alteridade}

Ciro Flamarion Cardoso (CARDOSO, 2005) apresenta este elemento no campo pós-moderno como sendo um artifício metodológico para justificar o seu próprio campo: a pós-modernidade e o modo de produção vigente.

O conceito de alteridade, bastante presente entre os trabalhos de ciências humanas de caráter etno-históricos, nos remete ao relacionamento diante do "outro", se identificando ao não idêntico, ou seja, apresenta-se uma perspectiva de identidade a partir do "não ser" o "outro". Diante deste apresentar de palavras trocadas, a idéia de alteridade, mesmo que reconheça a existência do diferente, o entende como parte constitutiva do ser diante desses "outros" o que pode sugerir uma espécie de harmonização diante das "representações" do outro, o que por sua vez pode nos levar ao velamento dos conflitos sociais de classe antagônicas, pois a pluralidade de "outros" seria o campo privilegiado da construção da identidade do ser.

Desta forma, o intelectual pós-moderno apresenta-nos um ideal bastante perverso diante do concreto, pois esconde com este termo a luta de classes como um dos elementos constitutivos da História do Ser Social, contribuindo para a manutenção de uma classe privilegiada (harmonizadora dos conflitos sociais) ao lado de outra classe, desprivilegiada, na sociedade do mercado

\footnotetext{
${ }^{5}$ Tratei mais aprofundadamente sobre esse tema em minha dissertação. Ver, MENEZES, 2009.
} 
(receptora da ideologia da harmonia diante do "outro" no paradigma pósmoderno).

Metodologicamente, como estratégia, o intelectual pós-moderno defende a alteridade como forma de manter-se no campo cognitivo como um inocente "outro" que compõe a pluralidade teórica e metodológica, quando na realidade se utiliza deste argumento para sobrepor-se as demais perspectivas teóricas e metodológicas, principalmente no que se refere ao materialismo histórico e dialético.

\section{A estratégia pós-moderna no tempo presente}

O discurso e a prática da pós-modernidade é capaz de nos rechear com uma série de episódios adocicados as concupiscências da economia globalizada. Neste contexto observamos os vieses das propagandas acadêmicas onde se cultua a perspectiva da narrativa como ato criador da produção alicerçada no idealismo antropológico que abarca olhares metasubjetivos para a História e seus eventos objetivamente pregadores de um homem concreto e sujeito da e na História.

O pensamento pós-moderno postula uma série de valores subjetivos e infundados sobre o lluminismo quando se pauta em desenvolver a crítica ao racionalismo burguês. Um posicionamento contraditório, uma vez que o pensamento pós-moderno é fruto do desenvolvimento da ideologia da modernidade. Ou seja, um desdobramento das ideologias no sistema econômico do capital, onde projetar-se visando à emancipação do homem torna-se algo combativo a sua necessidade de alienação social. Pois seria o mesmo que alimentar o processo de consciência da sociedade globalizada e consumidora de mercadorias, rumo a desalienação.

Desta forma, a pós-modernidade lança a culpa pelos desastres do atual sistema global ao racionalismo do século XVIII, ao técnico-cientificismo do século XX, para ocultar o seu real objeto de combate que está no século XIX: o marxismo e seu projeto emancipatório do homem (ANDERSON, 1989). 
O conjunto de intelectuais que se identificam com o termo pós-moderno (entre eles, filósofos e historiadores) atacam o projeto emancipador proposto pelo racionalismo desde o século XVIII. Desenvolvem críticas a razão, colocando-a no banco dos réus e a condenando como incapaz de promover a liberdade e o bem humano (FUKUYAMA, 1992: 350-351). Atribuindo-Ihe assim, a responsabilidade por todos os desastres da humanidade: guerras; poluições; desigualdades políticas, econômicas e sociais; entre as desgraças de todos os tipos e formas. Combatem ainda as visões holísticas e estruturais da história.

Assim, defendem o estudo dos recortes, das representações subjetivas, pois quase sempre são críticos da visão coletiva de um "fenômeno". Abandonam o homem como sujeito por considerarem que este está submetido ao controle estrutural da sociedade e da economia. Gerando assim um pessimismo, sem esperanças de transformações da sociedade globalizada.

Diante destas frustrações, os intelectuais pós-modernos se apresentam incapazes de reordenar a situação catastrófica que estes mesmos identificam na história do presente. Qual seria o elemento ou conjunto destes que, de fato, impedem os pós-modernos de atuarem como intelectuais engajados além de movimentos recortados do todo, como os "movimentos de minorias"?

Buscando a objetividade, é possível operar um outro problema a lado de uma hipótese: Qual é a contribuição dos postulados teóricos da pósmodernidade para o presente? Seria pertinente verificarmos qual é a possibilidade desta ideologia ser uma forma/instrumento de cristalização do próprio projeto do racionalismo burguês, diante de todos os seus erros e catástrofes auferidas ao homem no decorrer destes últimos séculos. E ainda, em que medida o discurso da pós-modernidade não é caminho direto para a consolidação da sociedade de consumo capitalista e também uma ação prática que se utiliza do subjetivo para minar as possibilidades de concretização do projeto emancipador do homem através marxismo apresentado desde o século $\mathrm{XIX}$ ?

$O$ ataque ao lluminismo possui fraca ressonância, uma vez que poucas vozes se apresentam para defendê-lo. Por quê? Seria por estarem eles 
mesmos utilizando a roupagem do pós-modernismo para se safarem das responsabilidades diante da História e do sujeito?

É possível observar um desesperado combate aos projetos desalienadores (GRAMSCI, 1984) em defesa de que o homem emancipado e sua proposta ficaram no pretérito, distante das novas realidades e dificuldades que o mundo nos apresenta hoje. Portanto, já não importa mais quem seja você ou o outro. O que vale é sentir-se vivo e funcional diante do todo. Viver a espera de uma visão de mundo romântico, onde o amanhã dependa das ações do hoje seria minimamente perca de tempo diante da concepção de homem na pseudo pós-modernidade.

Diante deste quadro, o pós-moderno, seus intelectuais e seus discursos camaleões mutantes acabam por instigar a inércia política, o contentamento funcional diante da economia e o embrutecimento da sociedade. Efeitos perfeitamente excepcionais para a reprodução do capital em qualquer paisagem humana a desumanizar-se a qualquer instante.

A indústria cultural (ADORNO \& HORKHEIMER, 1985: 113-156) passa a fundir-se com esta proposta fragmentada de existência pós-moderna, promovendo a massificação da ideologia de consumo no capitalismo, gerando o tipo de homem ideal para o sistema: o Homo symbolicus (CARDOSO, 2005: 282). Cristalizando todas as problemáticas que o próprio discurso pós-moderno identifica na organização da sociedade atual como sendo obras da modernidade que decretara o seu próprio fim.

Desde então, a culpa não é "nossa", é do iluminismo!

\section{Considerações finais}

Pretendeu-se com o artigo, apresentar algumas contribuições sobre o debate acerca do paradigma pós-moderno de forma crítica, apontando alguns de seus elementos. Pretendeu-se, ao mesmo passo, apresentar aos alunos de graduação, uma introdução ao debate sobre essas pretensas teorias sociais, sem as devidas citações de seus intelectuais, nos ocupando de apresentar a intelectualidade diante de uma perspectiva coletiva e bastante diversa. 
Evidentemente, a abordagem deve ser estendida, mas reafirmamos, tratou-se de um texto introdutório ao debate teórico mais profundo.

\section{Referências}

ADORNO, THEODOR W. \& HORKHEIMER, MAX. Dialética do esclarecimento. Tradução de Guido Antonio de Almeida. Rio de Janeiro: Jorge Zahar Ed., 1985.

ANDERSON, Perry. Considerações sobre o marxismo ocidental. Tradução de Marcelo Levy. São Paulo: Brasiliense, 2ª edição, 1989.

CARDOSO, Ciro Flamarion. Um historiador fala de teoria e metodologia. Ensaios; Bauru-SP, EDUSC, 2005.

FUKUYAMA, Francis. O fim da história e o último homem. Trad. de Aluyde Soares Rodrigues. Rio de Janeiro: Rocco, 1992.

GRAMSCI, Antonio. Concepção Dialética da História. $5^{\mathrm{a}}$ edição. Trad. Carlos Nelson Coutinho. Rio de Janeiro, Civilização Brasileira, 1984.

KONDER, Leandro. Intelectuais Brasileiros \& Marxismo. Oficina de Livros: Belo Horizonte, 1991.

MENEZES, Jean Paulo Pereira de. Os Intelectuais, a política e suas perspectivas [...]. Dissertação de Mestrado, Programa de Pós-Graduação em História da Universidade Federal da Grande Dourados - MS, 2009.

MICELI, Sérgio. Intelectuais à Brasileira. São Paulo, Companhia das Letras, 2001.

MORAES, José Geraldo Vinci de. Conversas com historiadores brasileiros. São Paulo: Editora 34, 2001.

PONTES, Heloisa. Círculo de intelectuais e experiência social. In: Revista Brasileira de Ciências Sociais. Vol. 12, n. 34, 1997. p. 57-69.

PONTES, Heloísa. Destinos mistos. São Paulo: Companhia das Letras, 1998. 